\title{
New Triterpene and Antibacterial Labdenoic Acid Derivatives from Moldenhawera nutans
}

\author{
Juceni P. David, ${ }^{*, a}$ Jailton Ferrari, ${ }^{b}$ Jorge M. David, ${ }^{b}$ Alaíse G. Guimarães, ${ }^{a}$ \\ Fernanda W. de M. Lima a and Geórgia L. S. de Souza ${ }^{a}$ \\ ${ }^{a}$ Faculdade de Farmácia and ${ }^{b}$ Instituto de Química, Universidade Federal da Bahia, \\ 40170-290 Salvador-BA, Brazil
}

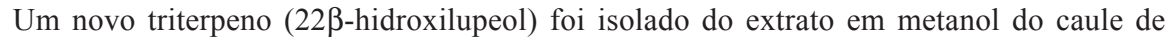
Moldenhawera nutans (Leguminosae) além de diterpenos derivados do ácido labdenóico de ocorrência comum nesta espécie. A partir do ácido labd-8(17)-en-15-óico foram preparados derivados com atividade in vitro discreta frente à Staphylococcus aureus, Pseudomonas aeruginosa, Escherichia coli, Salmonella cholerasuis e Vibrio parahaemolyticus.
\end{abstract}

A new triterpene derivative (22ß-hydroxylupeol) was isolated from the $\mathrm{MeOH}$ extract of stems of Moldenhawera nutans (Leguminosae) together with labdenoic acid derivatives of common occurrence in this species. From the labd-8(17)-en-15-oic acid were prepared simple derivatives, which exhibited in vitro weak activity against Staphylococcus aureus, Pseudomonas aeruginosa, Escherichia coli, Salmonella cholerasuis, and Vibrio parahaemolyticus.

Keywords: Moldenhawera nutans, Leguminosae, antibacterial labdene derivatives, 22ß-hydroxylupeol

\section{Introduction}

Genus Moldenhawera Schrard. (Leguminosae: Caesalpinoideae), endemic to Northeast Brazil, is represented by approximately ten species. ${ }^{1}$ Previous phytochemical study of $M$. nutans resulted in the isolation of four known labdene diterpenes besides a new bisditerpene named moldenin. ${ }^{2}$ The present work describes the results of the fractionation of the hexane phase obtained from the $\mathrm{MeOH}$ extract of M. nutans. Besides the known diterpenes previously isolated, it was also obtained the 3oxo-labd-8(17)-en-15-oic acid (1) as a methyl derivative (1a), and three triterpenes, lupeol, betulin, and the new lupane derivative (2). The labd-8(17)-en-15-oic acid (3) was the predominant compound in this extract. From this compound, derivatives (4-8) were prepared and some of them were submitted to in vitro antibacterial assays.

\section{Results and Discussion}

The structural elucidation of 1a (Figure 1) was based on MS, IR, and NMR data analyses. Comparison of NMR data of the methyl ester derivative with moldenin, ${ }^{2}$ methyl

*e-mail: juceni@ufba.br ent-3-oxo-labd-8(17)-en-15-oate ${ }^{3}$ and literature data ${ }^{4}$ allowed establishing the labdanic structure. The normal series of this compound was confirmed by positive optical rotation.

The HREIMS of $\mathbf{2}$ exhibited a molecular ion signal at $\mathrm{m} / \mathrm{z} 442.3829$, indicating the molecular formula $\mathrm{C}_{30} \mathrm{H}_{50} \mathrm{O}_{2}$ (requires 442.3811). The ${ }^{1} \mathrm{H}$ NMR data (Experimental section) showed characteristic signals of lupane triterpene, seven methyl groups, one isopropenyl $(\delta 4.61,4.71$, and $1.70)$ and two signals of oxymethine hydrogens $(\delta 3.68$ and 3.20). The ${ }^{13} \mathrm{C}$ NMR spectra (BB and DEPT $135^{\circ}$ ) displayed 30 signals and confirmed the data above through the resonances displayed at $\delta 19.3,109.8,150.3$, as well as at $\delta 78.0$ and 79.7 for the isopropenyl and two oxymethine groups, respectively. The presence of an additional oxymethine signal indicated that $\mathbf{2}$ is a hydroxylated lupeol derivative. The localization of the hydroxyl group at C-22 of the lupane framework was proposed by comparison with ${ }^{13} \mathrm{C}$ NMR data (Table 1) of 16-hydroxylupeol ${ }^{5}$ and the correlations observed in the long range HETCOR of H-22 $(\delta$ 3.68) and $\mathrm{C}-28(\delta$ 12.2), C-19 $(\delta$ 45.9) and C-18 $(\delta 45.1)$ as well as by the carbon shifts observed in the diacetyl derivative (2a) (Table 1). Thus, the NMR spectra of 2a showed a shielding effect at C-21 $(\Delta \delta=-3.5 \mathrm{ppm})$, which is indicative that $\mathrm{C}-22$ bears a hydroxyl group. The 
insignificant effect observed at C-19 in the NMR spectra of 2a together with the coupling constants observed in the ${ }^{1} \mathrm{H}$ NMR suggested that the hydroxyl group is in equatorial position. The ${ }^{1} \mathrm{HNMR}$ nOe difference spectra of this compound permitted to corroborate the proposition. When the $\mathrm{H}-22$ was irradiated it was possible to assign increments in $\mathrm{H} \alpha-21(25 \%), \mathrm{H}-29(3 \%)$ and, $\mathrm{H}-19(10 \%)$. These findings are indicative that all the affected protons were in the same plane. The fragmentation pattern observed in the MS of $\mathbf{2}$ was also indicative of a hydroxyl group in C-22 of the cyclopentyl ring, especially by mass fragments of $\mathbf{2}$ at $m / z 374$ and 2a at $m / z 458$ (Figure 2).

Since labd-8(17)-en-15-oic acid (3) showed antibacterial activity (Table 2), some of its simple chemical derivatives were prepared and also evaluated. Derivative 3 was refluxed with $\mathrm{MeOH} / \mathrm{HCl}$ to obtain the isomeric methyl esters $4 \mathbf{a}$ and

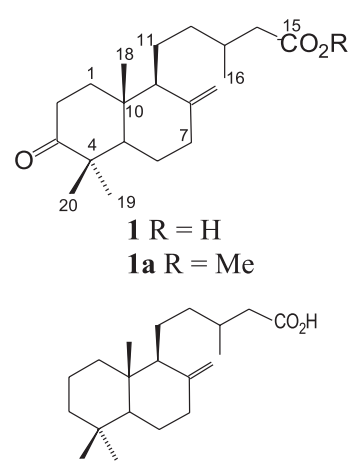

3

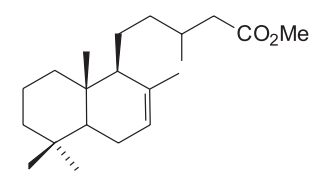

5

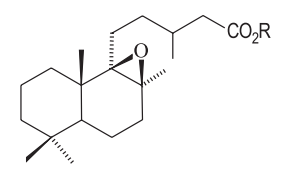

$7 \mathrm{R}=\mathrm{H}$

$7 \mathrm{a} \mathrm{R}=\mathrm{Me}$

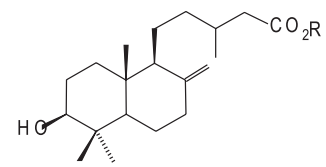

$9 \mathrm{R}=\mathrm{H}$

9a $\mathrm{R}=\mathrm{Me}$
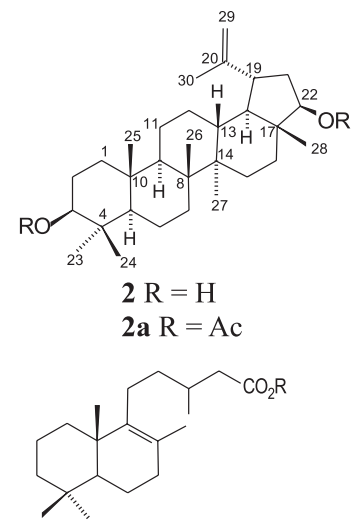

$4 \mathrm{R}=\mathrm{H}$

4a $\mathrm{R}=\mathrm{Me}$

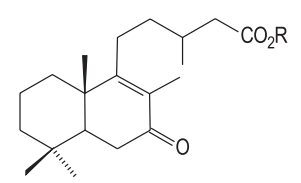

$6 \mathrm{R}=\mathrm{H}$

6a $\mathrm{R}=\mathrm{Me}$
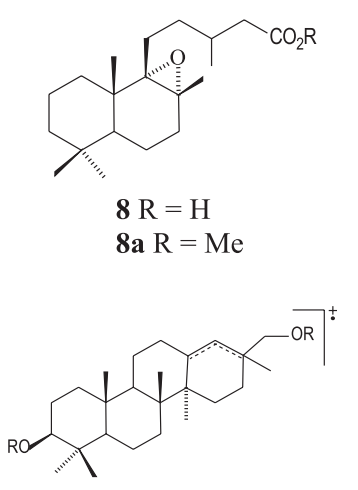

$\mathrm{R}=\mathrm{H} m / z 374$
Figure 1. Isolated compounds from Moldenhawera nutans, their derivatives and mass fragments of $\mathbf{2}$ and $\mathbf{2 a}$.
Table 1. ${ }^{13} \mathrm{C}$ NMR data for compounds 2, 2a and the model compound 16hydroxylupeol $^{5}[75 \mathrm{MHz}, \delta(\mathrm{ppm})]$

\begin{tabular}{|c|c|c|c|}
\hline $\mathrm{C}$ & 2 & $2 a$ & 16-hydroxylupeol \\
\hline 1 & 38.8 & 38.2 & 38.9 \\
\hline 2 & 27.5 & 23.5 & 27.4 \\
\hline 3 & 79.7 & 81.2 & 78.8 \\
\hline 4 & 39.1 & 37.7 & 38.9 \\
\hline 5 & 55.5 & 55.2 & 55.4 \\
\hline 6 & 18.4 & 18.0 & 18.3 \\
\hline 7 & 34.3 & 34.0 & 34.3 \\
\hline 8 & 40.7 & 40.7 & 41.0 \\
\hline 9 & 50.4 & 50.1 & 50.0 \\
\hline 10 & 37.1 & 36.9 & 37.1 \\
\hline 11 & 20.7 & 20.7 & 20.9 \\
\hline 12 & 25.2 & 24.7 & 24.9 \\
\hline 13 & 37.7 & 37.3 & $37.3^{*}$ \\
\hline 14 & 42.6 & 42.5 & 44.1 \\
\hline 15 & 27.2 & 26.3 & $36.9 *$ \\
\hline 16 & 33.7 & 33.3 & 76.9 \\
\hline 17 & 45.3 & 44.5 & 48.6 \\
\hline 18 & 45.1 & 44.7 & 47.7 \\
\hline 19 & 45.9 & 45.8 & 47.6 \\
\hline 20 & 150.3 & 149.1 & 149.8 \\
\hline 21 & 38.9 & 35.4 & 30.0 \\
\hline 22 & 78.0 & 80.8 & 37.8 \\
\hline 23 & 28.3 & 27.8 & 28.0 \\
\hline 24 & $16.0^{*}$ & 16.0 & 15.4 \\
\hline 25 & $16.1^{*}$ & 16.4 & 16.1 \\
\hline 26 & 15.9 & 15.8 & 16.1 \\
\hline 27 & 14.3 & 14.3 & 16.1 \\
\hline 28 & 12.2 & 12.6 & 11.8 \\
\hline 29 & 109.8 & 110.4 & 109.6 \\
\hline 30 & 19.3 & 19.1 & 19.4 \\
\hline OAc & & $170.9,171.0$ & \\
\hline OAc & & $21.1,21.2$ & \\
\hline $\mathrm{OMe}$ & & & \\
\hline
\end{tabular}

5. Next, 4a was submitted to allylic oxidation by $t$-butyl chromate $^{6}$ and furnished 6a. It was also prepared the epoxy derivatives $7 \mathbf{a}$ and $\mathbf{8 a}$ from $\mathbf{4 a}$ by reaction with MCPBA. The derivatives $7 \mathbf{a}$ and $8 \mathbf{a}$ are new and they were characterized by spectrometric analyses data. Compounds 1a, 2, 4a, and 6a-8a were submitted to antibacterial evaluation and none of them was active; while the acid derivatives $(\mathbf{1}, \mathbf{4 , 6 - 8})$ obtained after saponification, together with $\mathbf{9}$, a labdane previously obtained from this plant, showed moderate antibacterial activity at $90 \mu \mathrm{g}$ per disc (Table 2). These results indicate the need of the presence of an acid group for the antibacterial activity and also that structural features contribute to the inhibition area as well.

\section{Experimental}

\section{General procedures}

The ${ }^{1} \mathrm{H}$ and ${ }^{13} \mathrm{C}$ NMR, DEPT, COSY, and HETEROCOSY ( $J 140$ and $9 \mathrm{~Hz})$ spectra were obtained 
Table 2. Diameter of inhibition zones of compounds 1, 3, 4, 6-9 from $M$. nutans in agar diffusion test in $\mathrm{mg}$ per disk

\begin{tabular}{lccccc}
\hline & \multicolumn{5}{c}{$\phi / \mathrm{mm}$} \\
\cline { 2 - 6 } Sample & EC & SA & SC & VP & PA \\
\hline $\mathbf{1}$ & 7 & - & 10 & 8 & - \\
$\mathbf{3}$ & 8 & - & 15 & 15 & 13 \\
$\mathbf{4}$ & 20 & 20 & 8 & 35 & 6 \\
$\mathbf{6}$ & 15 & - & - & 12 & 13 \\
$\mathbf{7}+\mathbf{8}^{*}$ & 15 & - & - & 12 & - \\
$\mathbf{9}$ & - & - & 13 & - & - \\
Penicillin & 35 & - & 31 & - & 25 \\
Tetracycline & 35 & 15 & 36 & 34 & 30 \\
Chloramphenicol & 22 & - & 26 & 34 & 23
\end{tabular}

$\mathrm{EC}=$ Escherichia coli $; \mathrm{SA}=$ Staphylococus aureus $; \mathrm{SC}=$ Salmonella cholerasuis; $\mathrm{VP}=$ Vibrio parahaemolyticus; $\mathrm{PA}=$ Pseudomonas aeruginosa. *evaluation performed in mixture.

on a Varian Gemini 2000 instrument employing $\mathrm{CDCl}_{3}$ as both solvent and reference. The FTIR spectrum was recorded on a JASCO spectrophotometer Mod. Valor III. MS was recorded on a Micromass Autospec spectrometer (HRMS) and an HP model 5973 spectrometer (EIMS). Melting points were measured on a Microquímica MIAPF 301 apparatus and are uncorrected. Column chromatography was carried out on silica gel 60 and, silica gel TLC was used to monitor the fraction employing iodine fumes, Liberman-Buchard spray reagent, and UV light (254/366 $\mathrm{nm})$.

\section{Plant material}

The plant material of M. nutans were collected at sandy soil of Reserva do Parque da Lagoa do Abaeté, Salvador, BA, Brazil in the spring of 1997 and identified by Prof. Maria L. S. Guedes of Herbarium Alexandre Leal Costa, where a voucher (\#029057) is deposited.

\section{Extraction and isolation}

The powdered stem $(4 \mathrm{~kg})$ of Moldenhawera nutans was extracted with $\mathrm{MeOH}$. The methanol extract (153 g) was partitioned with hexane, furnishing $73.2 \mathrm{~g}$ of extract. The hexane phase was purified through $\mathrm{CC}$ over silica gel with mixtures of hexane/EtOAc as eluents. The fraction eluted with $5 \%$ of EtOAc furnished the labd-8(17)-en-15-oic acid (3, $42 \mathrm{~g})$. All the fractions eluted from the main CC $(7.3 \mathrm{~g})$ with hexane:EtOAc $(8: 2)$ were submitted to methylation using an ether solution of N-methyl-N-nitroso-p-toluenesulfonamide $\left(\right.$ Diazald $\left.^{\circledR}\right)$. The product of this reaction was then subjected to silica gel $\mathrm{CC}$ and from the fraction eluted with hexane:EtOAc $(9: 1)$ afforded $39.9 \mathrm{mg}$ of 1a (methyl 3-oxo-labd-8(17)-en-15-oate), lupeol (10.5 mg), and $22 \beta$-hydroxylupeol $(2,70.3 \mathrm{mg})$. The fraction eluted with hexane:EtOAc led to the isolation of $25.4 \mathrm{mg}$ of betulin $^{7}$ and methyl 3-hydroxy-labd-8(17)-en-15-oate (9a, $102 \mathrm{mg}$ ).

\section{Methyl 3-oxo-labd-8(17)-en-15-oate (1a)}

Pale yellow oil. $[\alpha]_{\mathrm{D}}^{25} 33.4^{\circ}$ ( $\mathrm{c} 0.1, \mathrm{CHCl}_{3}$ ), IR(film) $v_{\max } / \mathrm{cm}^{-1}: 3080,2950,1737,1706,1643,1385,1160,1008$, 890; $\mathrm{C}_{21} \mathrm{H}_{34} \mathrm{O}_{3}$ (Found: C, 75.1; H, 10.5\%. Requires: C, 75.4; H, 10.2\%), EIMS: $70 \mathrm{eV}$ (rel. int.) $m / z$ : $334\left[\mathrm{M}^{+}\right]$ (18), 319 (4), 303 (7), 233 (51), 220 (15), 205 (48), 177 (16), 163 (22), 137 (34), 135 (100), 123 (68), 109 (68); ${ }^{1} \mathrm{H}$ NMR (300 MHz, $\left.\mathrm{CDCl}_{3}\right): \delta 4.88$ (sl, 1H, H-17a), 4.55 (sl, 1H, H-17b), 3.64 (s, 3H, $\mathrm{OCH}_{3}$ ), 1.08 (s, 3H, Me-19), 1.01 (s, 3H, Me-18), 0.93 (d, J 6.6 Hz, 3H, Me-16), 0.85 (s, $3 \mathrm{H}, \mathrm{Me}-20) ;{ }^{13} \mathrm{C}$ NMR $\left(75 \mathrm{MHz}, \mathrm{CDCl}_{3}\right.$ ): $\delta 35.3(\mathrm{C}-1)$, 34.4 (C-2), 216.2 (C-3), 47.4 (C-4), 54.8 (C-5), 24.8 (C6), 37.6 (C-7), 146.9 (C-8), 55.6 (C-9), 39.0 (C-10), 21.1 (C-11), 37.3 (C-12), 30.5 (C-13), 41.5 (C-14), 173.2 (C15), 21.4 (C-16), 107.2 (C-17), 19.3 (C-18), 25.6 (C-19), $13.8(\mathrm{C}-20), 51.0\left(\mathrm{OCH}_{3}\right)$.

\section{2ß-Hydroxylupeol (2)}

White amorphous powder; $\mathrm{mp} 158-160{ }^{\circ} \mathrm{C} .[\alpha]_{\mathrm{D}}^{25} 71.2^{\circ}$ (c 0.1, $\mathrm{CHCl}_{3}$ ); IR(film) $v_{\text {max }} / \mathrm{cm}^{-1}: 3401,2934,2868,1643$, 1455, 1385, 880; HREIMS: $\mathrm{m} / \mathrm{z} 442.3829\left(\mathrm{C}_{30} \mathrm{H}_{50} \mathrm{O}_{2}\right.$ requires 442.3811), EIMS: $70 \mathrm{eV}$ (rel. int.) $\mathrm{m} / \mathrm{z}$ : $442\left[\mathrm{M}^{+}\right]$ (12), 427 (4), 374 (100), 291 (6), 273 (57), 247 (14), 234 (12), 219 (8), 207 (23), 189 (31), 175 (14), 161 (13), 147 (16), 135 (35), 121 (24), 107 (26); 'H NMR (300 MHz, $\left.\mathrm{CDCl}_{3}\right): \delta 4.71$ (m, 1H, H-29b), 4.61 (m, 1H, H-29a), 3.68 (t, $J 8.8 \mathrm{~Hz}, 1 \mathrm{H}, \mathrm{H}-22), 3.20$ (dd, $J 10.7$ and $5.6 \mathrm{~Hz}, 1 \mathrm{H}$, H-3), 2.46 (m, 1H, H-19), 1.70 (s, 3H, Me-30), 1.60 (m, 1H, H-5), 1.06 (s, 3H, Me-23), 0.98 (s, 3H, Me-24), 0.94 (s, 3H, Me-26), 0.85 and 0.84 (s, $3 \mathrm{H}$ each, Me-28 or Me27), 0.79 (s, 3H, Me-25); ${ }^{13} \mathrm{C}$ NMR (75 MHz, $\mathrm{CDCl}_{3}$ ): see Table 1.

\section{Preparation of derivatives}

\section{Acetylation of 22ß-hydroxylupeol (2)}

Compound $2(15.0 \mathrm{mg})$ was added to a solution of pyridine $(0.5 \mathrm{~mL})$ and acetic anhydride $(2.0 \mathrm{~mL})$ and the mixture was left at room temperature for $24 \mathrm{~h}$. Cold $\mathrm{H}_{2} \mathrm{O}$ was added and the diacetyl derivative (2a, $14.3 \mathrm{mg}$ ) was extracted with $\mathrm{CHCl}_{3}$.

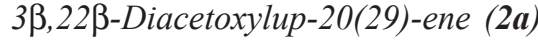

Oil, EIMS: $70 \mathrm{eV}$ (rel. int.) m/z: $526\left[\mathrm{M}^{+}\right]$(35), 466 (42), 458 (50), 416 (46), 398 (10), 289 (21), 276 (39), 249 
(19), 216 (38), 201 (50), 189 (95), 161 (27), 135 (58), 107 (42); ${ }^{1} \mathrm{H}$ NMR (300 MHz, $\left.\mathrm{CDCl}_{3}\right): \delta 4.70(\mathrm{sl}, 1 \mathrm{H}, \mathrm{H}-29 \mathrm{~b})$, 4.60 (sl, 1H, H-29a), 4.65 (t, J 8.9 Hz, 1H, H-22), 4.46 (dd, $J 10.9$ and $5.8 \mathrm{~Hz}, 1 \mathrm{H}, \mathrm{H}-3), 2.48$ (m, 1H, H-19), 2.04 (s, 3H ), 2.03 (s, 3H), 1.69 (sl, 3H, Me-30), 1.03 (s, $3 \mathrm{H}, \mathrm{Me}-23$ ), 0.92 (s, 3H, Me-24 and Me-26), 0.85, 0.84 and 0.83 (s, $3 \mathrm{H}$ each, Me-28 or Me-27 or Me-25); ${ }^{13} \mathrm{C}$ NMR $\left(75 \mathrm{MHz}, \mathrm{CDCl}_{3}\right)$ : see Table 1.

Preparation of derivatives of labd-8(17)-en-15-oic acid (3) Compound $3(1.0 \mathrm{~g})$ was refluxed with $36 \mathrm{~mL}$ of an acidic methanolic solution $(\mathrm{HCl} 0.048 \mathrm{~N})$ under stirring for $4.5 \mathrm{~h}$. Sequentially, water was added and the solution was extracted with $\mathrm{CHCl}_{3}$. The product was submitted to $\mathrm{Si}$ gel with $\mathrm{AgNO}_{3} \mathrm{CC}$ and eluted with hexane:EtOAc (9:1). This procedure furnished $489.4 \mathrm{mg}$ of methyl labd-8-en-15-oate ${ }^{8}(\mathbf{4 a}, 49 \%)$ and $210 \mathrm{mg}$ of methyl labd-7-en-15-oate ${ }^{9}$ (5a, 21\%). Methyl labd-8-en-15-oate (4a, $480 \mathrm{mg}$ ) was diluted to $11 \mathrm{~mL}$ of $\mathrm{CCl}_{4}$ and sequentially added with $3.5 \mathrm{~mL}$ of acetic acid, $2.0 \mathrm{~mL}$ of acetic anhydride, and $4.5 \mathrm{~mL}$ of solution of terc-butyl chromate freshly prepared by established procedures. ${ }^{6}$ The system was refluxed for 90 minutes followed by the addition of $21 \mathrm{~mL}$ of an oxalic acid (5\%) aqueous solution. The mixture was stirred until two layers were produced and next it was extracted with $\mathrm{CHCl}_{3}$. The organic phase was recovered and washed with a $10 \%$ solution of $\mathrm{Na}_{2} \mathrm{CO}_{3}$ and yielded $243.1 \mathrm{mg}$ of methyl 7oxo-labd-8-en-15-oate ${ }^{10}(6 \mathbf{a}, 50 \%)$. In parallel, to a solution of $100 \mathrm{mg}$ of $\mathbf{4 a}$ in $4 \mathrm{~mL}$ of $\mathrm{CH}_{2} \mathrm{Cl}_{2}$ was added another solution of $80 \mathrm{mg}$ MCPBA in $4 \mathrm{~mL}$ of dichloromethane and the mixture was stirred for 30 minutes. Next, purification of the mixture reaction product through $\mathrm{CC}$ over $\mathrm{Al}_{2} \mathrm{O}_{3}$ with hexane/EtOAc (7:3) as an eluent, furnished compounds $7 \mathbf{a}(24.3 \mathrm{mg})$ and $\mathbf{8 a}(15.8 \mathrm{mg})$.

\section{Methyl labd-8-en-15-oate (4a)}

Oil. $[\alpha]_{D}^{25} 60.2^{\circ}\left(c 0.8, \mathrm{CHCl}_{3}\right)$; IR(film) $v_{\max } / \mathrm{cm}^{-1}$ : 2947, 2926, 1741, 1643, 1459, 1154, 887; $\mathrm{C}_{21} \mathrm{H}_{36} \mathrm{O}_{2}$, EIMS: $70 \mathrm{eV}$ (rel. int.) $m / z$ : $320\left[\mathrm{M}^{+}\right]$(13), 305 (24), 264 (5), 196 (10), 191 (100), 177 (13), 163 (15), 149 (28), 135 (33), 121 (53), 109 (47); ${ }^{1} \mathrm{H}$ NMR (300 MHz, $\left.\mathrm{CDCl}_{3}\right): \delta 3.67$ (s, 3H, $\mathrm{OCH}_{3}$ ), 1.54 (s, 3H, Me-17), 0.97 (d, J $6.4 \mathrm{~Hz}, 3 \mathrm{H}$, Me-16), 0.87 (s, 3H, Me-19), 0.83 (s, 3H, Me-18) and 0.79 (s, 3H, Me-20); ${ }^{13} \mathrm{C}$ NMR (75 MHz, $\left.\mathrm{CDCl}_{3}\right): \delta 33.6$ (C-1), 19.1 (C-2), 39.5 (C-3), 33.3 (C-4), 51.8 (C-5), 25.4 (C-6), 36.9 (C-7), 125.4 (C-8), 140.4 (C-9), 38.9 (C-10), 19,0 (C-11), 41.4 (C-12), 31.5 (C-13), 37.3 (C-14), 173.6 (C-15), 19.0 (C-16), 20.1 (C-17), 21.7 (C-18), 33.3 (C19), $19.6(\mathrm{C}-20), 51.9\left(\mathrm{OCH}_{3}\right)$.
Methyl labd-7-en-15-oate (5a)

Oil. $[\alpha]_{\mathrm{D}}^{25} 30.2^{\circ}\left(c 0.2, \mathrm{CHCl}_{3}\right), \mathrm{C}_{21} \mathrm{H}_{36} \mathrm{O}_{2}$, EIMS: 70 $\mathrm{eV}$ (rel. int.) m/z: $320\left[\mathrm{M}^{+}\right]$(9), 305 (15), 196 (12), 191 (52), 177 (6), 163 (10), 149 (15), 135 (20), 122 (100), 109 (84); ${ }^{1} \mathrm{H}$ NMR (300 MHz, $\left.\mathrm{CDCl}_{3}\right): \delta 5.39(\mathrm{sl}, 1 \mathrm{H}, \mathrm{H}-7)$, 3.66 (s, 3H, $\mathrm{OCH}_{3}$ ), 1.68 (s, 3H, Me-17), 0.97 (d, $J 6.5$ $\mathrm{Hz}, 3 \mathrm{H}, \mathrm{Me}-16), 0.84$ (s, 3H, Me-19), 0.81 (s, 3H, Me-18) and 0.78 (s, 3H, Me-20); ${ }^{13} \mathrm{C}$ NMR (75 MHz, $\left.\mathrm{CDCl}_{3}\right): \delta$ 39.2 (C-1), 19.0 (C-2), 42.2 (C-3), 32.7 (C-4), 54.7 (C-5), 23.8 (C-6), 122.1 (C-7), 135.1 (C-8), 49.8 (C-9), 36.6 (C10), 25.3 (C-11), 37.1 (C-12), 30.8 (C-13), 41.7 (C-14), 172.9 (C-15), 18.5 (C-16), 22.2 (C-17), 21.7 (C-18), 33.1 (C-19), 13.5 (C-20), $51.7\left(\mathrm{OCH}_{3}\right)$.

\section{Methyl 7-oxo-labd-8-en-15-oate (6a)}

Oil. $[\alpha]_{\mathrm{D}}^{25} 41.1^{\circ}\left(c\right.$ 1.0, $\left.\mathrm{CHCl}_{3}\right)$; IR(film) $v_{\max } / \mathrm{cm}^{-1}$ : 2953, 1736, 1661, 1605, 1461, 1437, 1156, 1080, 1007; $\mathrm{C}_{21} \mathrm{H}_{34} \mathrm{O}_{3}$, EIMS: $70 \mathrm{eV}$ (rel. int.) $\mathrm{m} / \mathrm{z}$ : $334\left[\mathrm{M}^{+}\right](30)$, 303 (7), 233 (52), 220 (15), 205 (44), 177 (10), 163 (10), 149 (13), 135 (100), 123 (48), 109 (56); ${ }^{1} \mathrm{H}$ NMR $\left(300 \mathrm{MHz}, \mathrm{CDCl}_{3}\right): \delta 3.56\left(\mathrm{~s}, 3 \mathrm{H}, \mathrm{OCH}_{3}\right), 1.62(\mathrm{~s}, 3 \mathrm{H}$, Me-17), 0.90 (d, J 6.4 Hz, 3H, Me-16), 0.96 (s, 3H, $\mathrm{Me}-19), 0.80$ (s, 3H, Me-18) and 0.76 (s, 3H, Me-20); ${ }^{13} \mathrm{C}$ NMR (75 MHz, $\left.\mathrm{CDCl}_{3}\right): \delta 35.7^{*}(\mathrm{C}-1), 18.5(\mathrm{C}-2)$, 41.2 ${ }^{*}$ (C-3), 33.0 (C-4), 50.1 (C-5), 35.2* (C-6), 200.0 (C-7), 129.7 (C-8), 168.0 (C-9), 40.8 (C-10), 26.9 (C11), 35.1 (C-12), 31.3 (C-13), $41.0^{\#}$ (C-14), 173.1 (C15), 19.4 (C-16), 11.2 (C-17), 21.2 (C-18), 32.4 (C19), $18.1(\mathrm{C}-20), 51.3\left(\mathrm{OCH}_{3}\right)$, *\# values may be interchangeable.

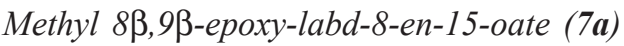

Oil. $[\alpha]_{\mathrm{D}}^{25} 38.2^{\circ}\left(c 0.8, \mathrm{CHCl}_{3}\right), \mathrm{C}_{21} \mathrm{H}_{36} \mathrm{O}_{3}$, EIMS: 70 $\mathrm{eV}$ (rel. int.) $\mathrm{m} / z$ : $336\left[\mathrm{M}^{+}\right]$(14), 321 (10), 305 (7), 278 (15), 264 (20), 253 (25), 251 (23), 235 (20), 207 (100), 177 (18), 163 (25), 149 (58), 125 (57), 121 (35), 109 (47); ${ }^{1} \mathrm{H}$ NMR (300 MHz, $\left.\mathrm{CDCl}_{3}\right): \delta 3.53\left(\mathrm{~s}, 3 \mathrm{H}, \mathrm{OCH}_{3}\right), 1.13$ (s, 3H, Me-17), 0.89 (d, J 6.4 Hz, 3H, Me-16), 0.96, 0.78 (s, 3H, Me-19 and Me-18) and $0.76(s, 3 \mathrm{H}, \mathrm{Me}-20) ;{ }^{13} \mathrm{C}$ NMR (75 MHz, $\mathrm{CDCl}_{3}$ ): $\delta 33.2$ (C-1), 17.2 (C-2), 41.5 (C-3), 32.8 (C-4), 42.3 (C-5), 23.9 (C-6), 43.5 (C-7), 62.2 (C-8), 72.2 (C-9), 38.5 (C-10), 18.4 (C-11), 41.4 (C-12), 31.0 (C-13), 35.1 (C-14), 173.5 (C-15), 19.6 (C-16), 21.2 (C-17), 21.9 (C-18), 33.5 (C-19), 17.2 (C-20), 51.3 $\left(\mathrm{OCH}_{3}\right)$.

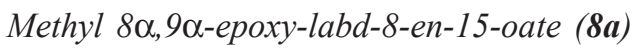

Oil. $\mathrm{C}_{21} \mathrm{H}_{36} \mathrm{O}_{3}$. $[\alpha]_{\mathrm{D}}^{25} 42.2^{\circ}\left(c 0.6, \mathrm{CHCl}_{3}\right)$, EIMS: 70 $\mathrm{eV}$ (rel. int.) $\mathrm{m} / z$ : $336\left[\mathrm{M}^{+}\right]$(15), 321 (13), 305 (6), 278 (15), 264 (23), 253 (26), 251 (26), 235 (18), 207 (100), 177 (18), 163 (22), 149 (62), 125 (59), 121 (36), 109 (52); 
${ }^{1} \mathrm{H}$ NMR (300 MHz, $\mathrm{CDCl}_{3}$ ): $\delta 3.53\left(\mathrm{~s}, 3 \mathrm{H}, \mathrm{OCH}_{3}\right), 1.24$ (s, 3H, Me-17), 0.90 (d, J 6.4 Hz, 3H, Me-16), 1.00, 0.80 (s, 3H, Me-19 and Me-18) and 0.74 (s, $3 \mathrm{H}, \mathrm{Me}-20) ;{ }^{13} \mathrm{C}$ NMR (75MHz, $\left.\mathrm{CDCl}_{3}\right): \delta 33.4$ (C-1), 16.7 (C-2), 41.4 (C-3), 33.6 (C-4), 53.8 (C-5), 29.2 (C-6), 29.0 (C-7), 64.7 (C-8), 72.5 (C-9), 38.7 (C-10), 19.7 (C-11), 41.4 (C-12), 31.4 (C-13), 37.0 (C-14), 173.5 (C-15), 19.5 (C-16), 21.4 (C-17), 21.9 (C-18), 33.2 (C-19), 16.5 (C-20), 51.3 $\left(\mathrm{OCH}_{3}\right)$.

Hydrolyses of the ester derivatives

All the methyl ester derivatives were submitted to hydrolysis by adding $1.5 \mathrm{~mL}$ of a solution of $10 \mathrm{mg} \mathrm{NaOH}$ in $\mathrm{H}_{2} \mathrm{O} / \mathrm{EtOH}(1: 1)$ to $10 \mathrm{mg}$ of each compound for 30 minutes. After this time, the reaction medium was saturated with $3 \mathrm{~mL}$ of brine and the produced ppted was acidified with $4 \mathrm{~mL}$ of an aqueous solution of $\mathrm{H}_{2} \mathrm{SO}_{4}$ and extracted with $\mathrm{CHCl}_{3}$. The organic phase was washed and dried over $\mathrm{NaSO}_{4}$, yielding acid compounds.

Antibacterial assays

This assay was performed by disc diffusion method using the established protocol. ${ }^{11}$ The antibacterial activity using paper disk with $\phi 9 \mathrm{~mm}$ was determined through the microorganism growth inhibition halo for Staphylococcus aureus (ATCC 10708), Pseudomonas aeruginosa (ATTCC 15442), Escherichia coli (ATCC 112229), Salmonella cholerasuis (ATCC 10708), and Vibrio parahaemolyticus (ATCC 17802) under the action of test substances $(90 \mathrm{mg})$. Penicillin $(10 \mathrm{mg})$, tetracycline $(30 \mathrm{mg})$ and chloramphenicol $(30 \mathrm{mg})$ were used as positive controls.

\section{Supplementary Information}

Supplementary data of 1a, 2, 2a, 4a and $\mathbf{6 a}$ as ${ }^{13} \mathrm{C}$ and ${ }^{1} \mathrm{H}$ NMR spectra are available free of charge at http://jbcs.sbq.org.br, as PDF file.

\section{Acknowledgments}

The authors are grateful to Conselho Nacional de Desenvolvimento Científico e Tecnológico - CNPq (Brazil), FAPESB and Fundação Coordenação de Aperfeiçoamento de Pessoal de Nível Superior (CAPES) for fellowship support and grants. We are in debt to Dr. Ignacio Lopez of Universidad de Extremadura, Badajoz, Spain for HREIMS.

\section{References}

1. Queiroz, L. P.; Lewis, G. P.; Allkin, R.; Kew Bull. 1999, $54,817$.

2. David, J. P.; David, J. M.; Yang, S-W.; Cordell, G. A.; Phytochemistry 1999, 50, 443.

3. Branco, A.; Pinto, A. C.; Braz Filho, R.; An. Acad. Bras. Cienc. 2004, 76, 505.

4. Wehrli, F. W.; Nishida, T. In Fortschritte der Chemie Organischer Naturstoffe/Progress in the Chemistry of Organic Natural Products; Herz, W.; Grisebach, H.; Kirby, G. W., eds.; Springer-Verlag: New York, 1979; v. 36, p. 1.

5. Wenkert, E.; Baddeley, G. V.; Burfitt, I. R.; Moreno, L. N.; Org. Magn. Reson. 1978, 11, 337.

6. Pinto, A. C.; Pereira, A. L.; Kelecom, A.; Porreca, L. M.; Ribeiro, N. M.; Barnes, R. A.; Chem. Pharm. Bull. 1988, 36, 4689.

7. Mahato, S. B.; Kundu, A. P.; Phytochemistry 1994, 37, 1517.

8. Weyerstahl, P.; Marschall, H.; Weirauch, M.; Thefeld, K.; Surburg, H.; Flavor Fragrance J. 1998, 13, 295.

9. Pinto, A. C.; Braga, W. F.; Rezende, C. M.; Garrido, F. M. S.; Veiga Jr.; V. F.; Bergter, L.; Patitucci, M. L.; Antunes, O. A. C.; J. Braz. Chem. Soc. 2000, 11, 355.

10. De Pascual, J. T.; Bellido, I. S.; Basabe, P.; Marcos, I. S.; Ruano, I. F.; Urones, J. G.; Phytochemistry 1982, 21, 899.

11. Bauer, A. W.; Kirby, M. M.; Sherris, J. C.; Turck, M.; Am. J. Clin. Pathol. 1966, 45, 493.

Received: February 23, 2007 Web Release Date: December 12, 2007 
New Triterpene and Antibacterial Labdenoic Acid Derivatives from Moldenhawera nutans

Juceni P. David, ${ }^{*, a}$ Jailton Ferrari, ${ }^{b}$ Jorge M. David, ${ }^{b}$ Alaíse G. Guimarães, ${ }^{a}$ Fernanda W. de M. Lima a and Geórgia L. S. de Souza ${ }^{a}$

${ }^{a}$ Faculdade de Farmácia and ${ }^{b}$ Instituto de Química, Universidade Federal da Bahia, 40170-290 Salvador-BA, Brazil

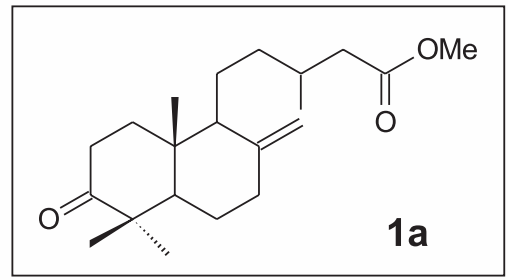

$1 \mathrm{a}$

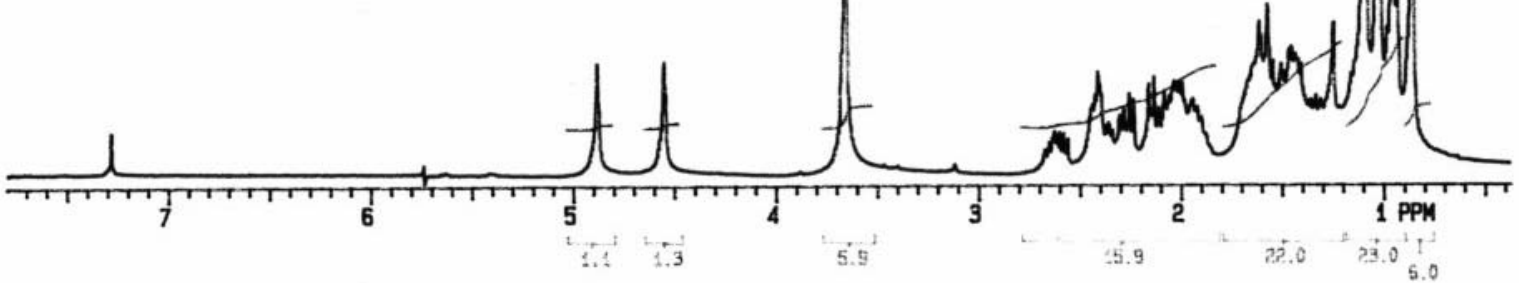

Figure S1. ${ }^{1} \mathrm{H} \mathrm{NMR}$ of compound 1a $\left[300 \mathrm{MHz}, \mathrm{CDCl}_{3}, \delta(\mathrm{ppm})\right]$. 

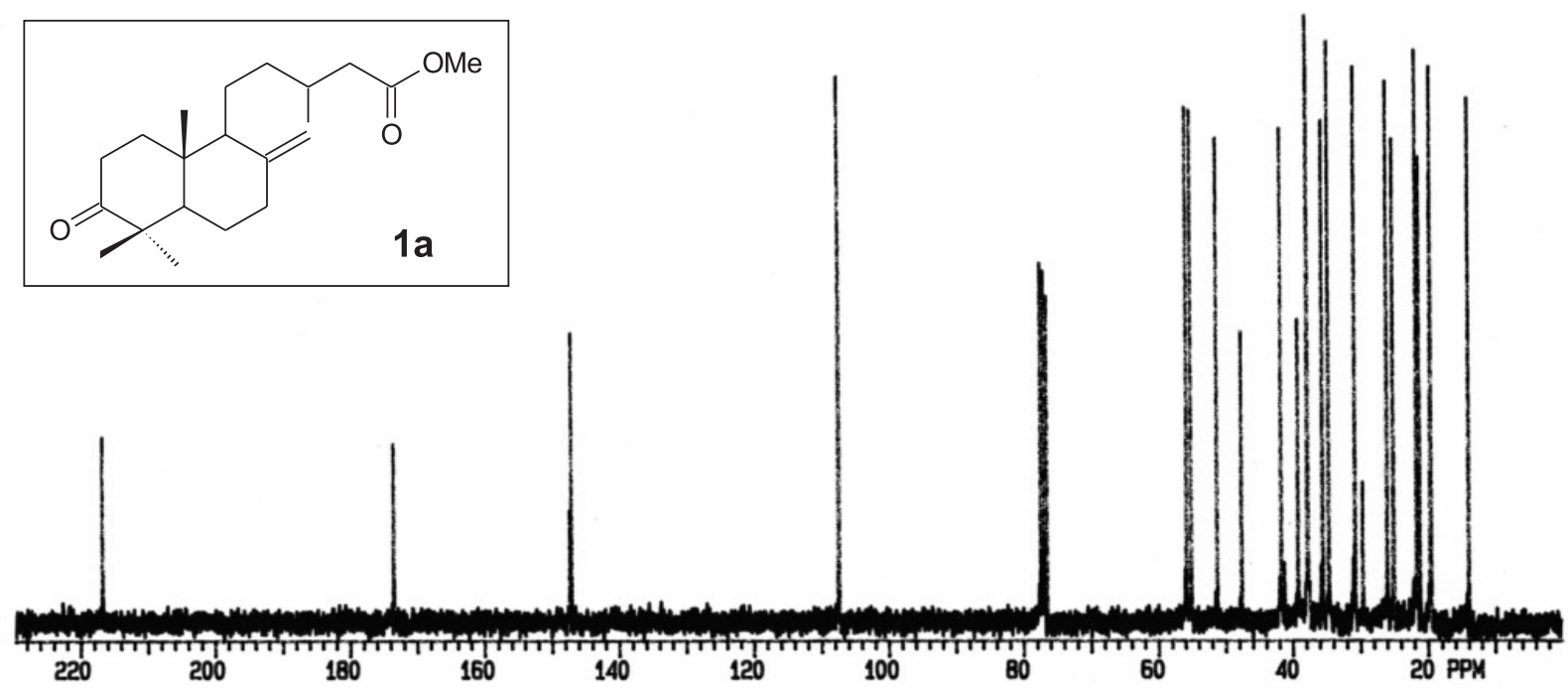

Figure S2. ${ }^{13} \mathrm{C}$ NMR of compound 1a $\left[75 \mathrm{MHz}, \mathrm{CDCl}_{3}, \delta(\mathrm{ppm})\right]$.
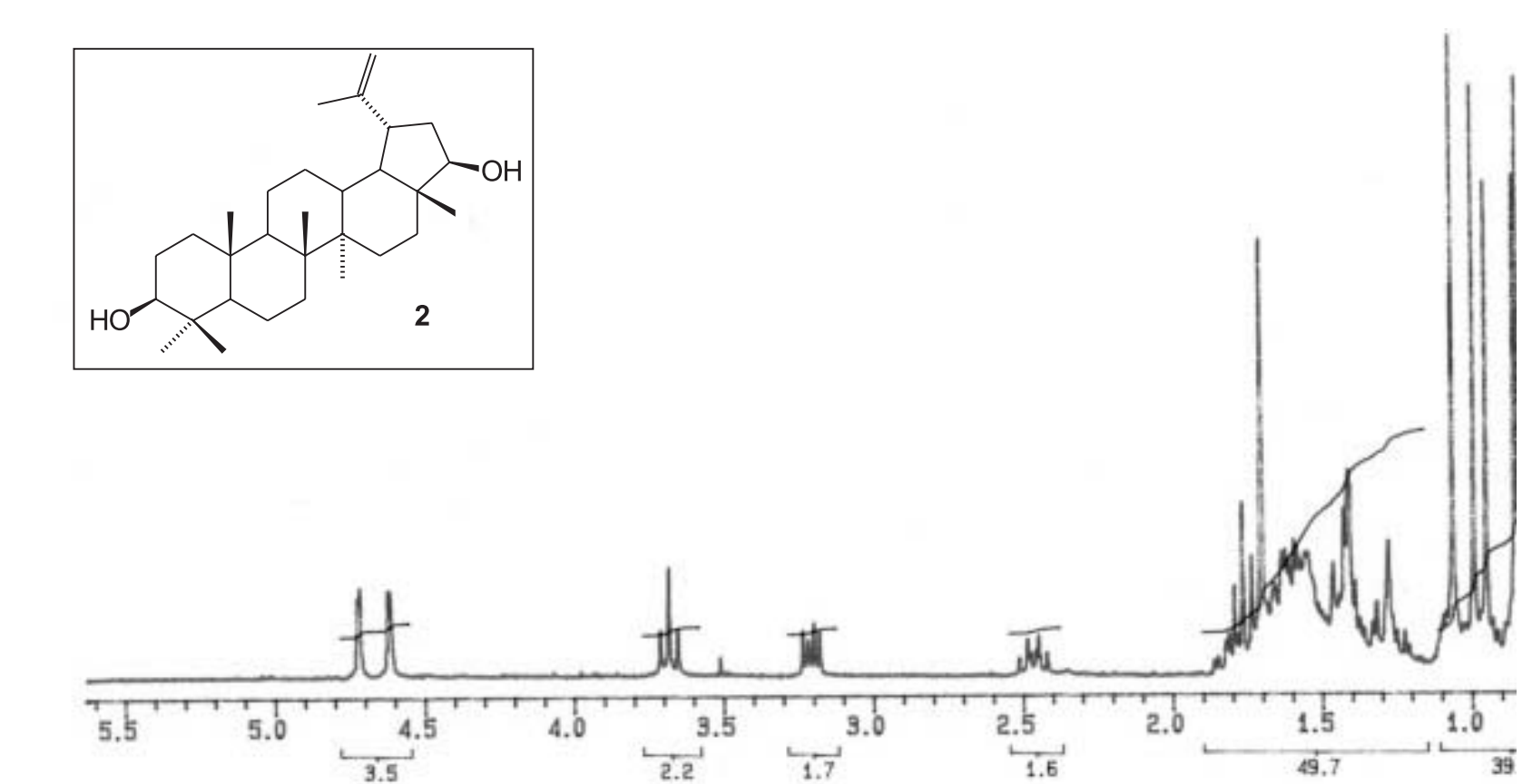

Figure S3. ${ }^{1} \mathrm{H} \mathrm{NMR}$ of compound $2\left[300 \mathrm{MHz}, \mathrm{CDCl}_{3}, \delta\right.$ (ppm)].

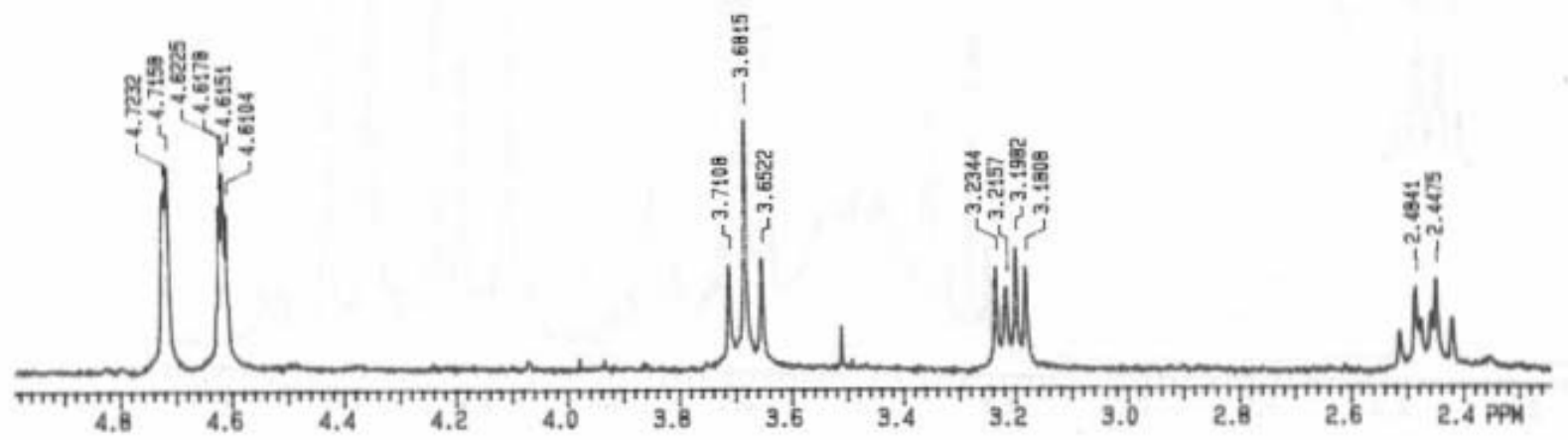

Figure S4. ${ }^{1} \mathrm{H}$ NMR of compound $2\left[300 \mathrm{MHz}, \mathrm{CDCl}_{3}, \delta(\mathrm{ppm})\right]$. 

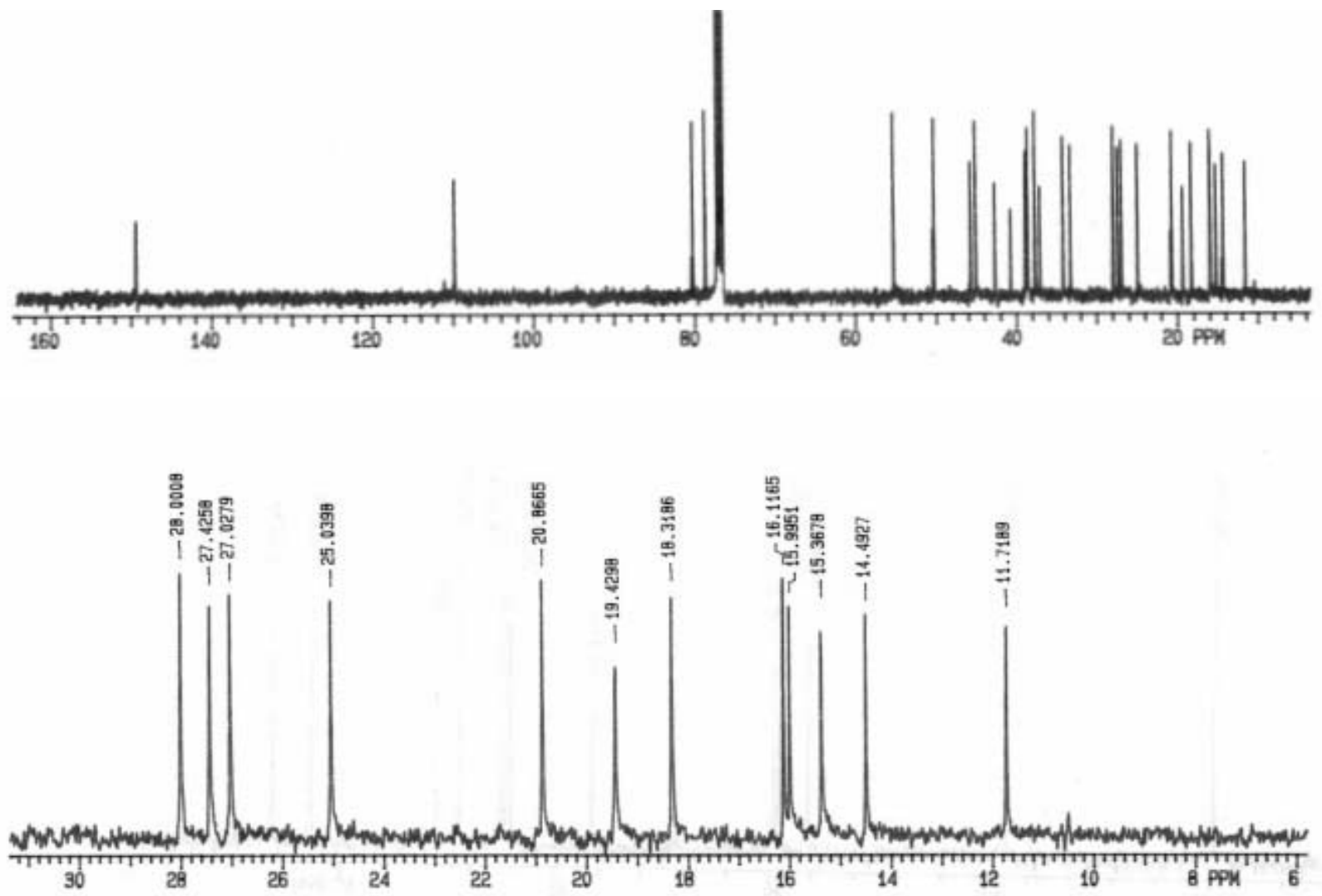

Figure S5. ${ }^{13} \mathrm{C}$ NMR of compound $2\left[75 \mathrm{MHz}, \mathrm{CDCl}_{3}, \delta(\mathrm{ppm})\right]$.
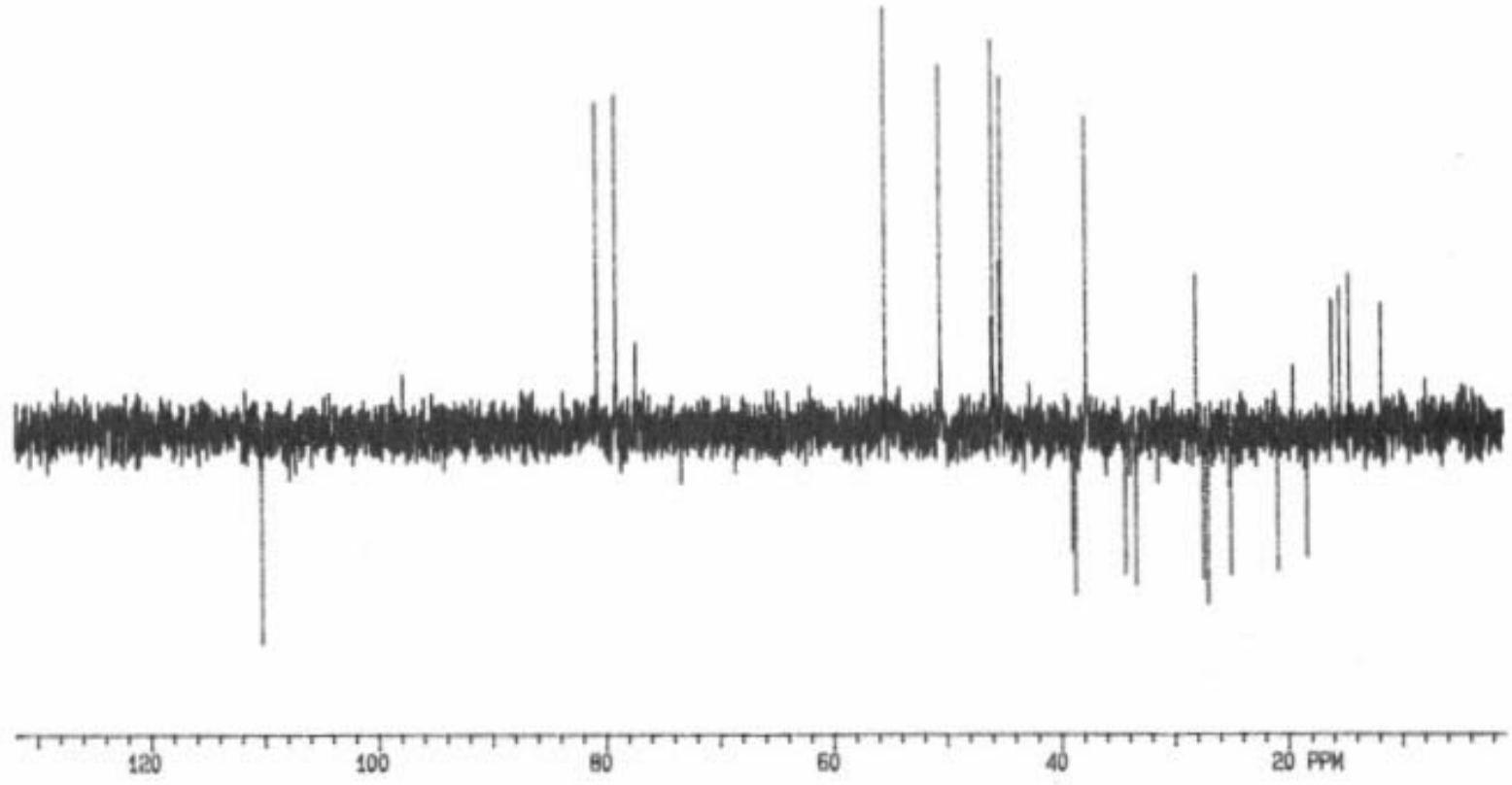

Figure S6. DEPT $135 \mathrm{NMR}$ spectra of compound $2\left[75 \mathrm{MHz}, \mathrm{CDCl}_{3}, \delta(\mathrm{ppm})\right]$. 


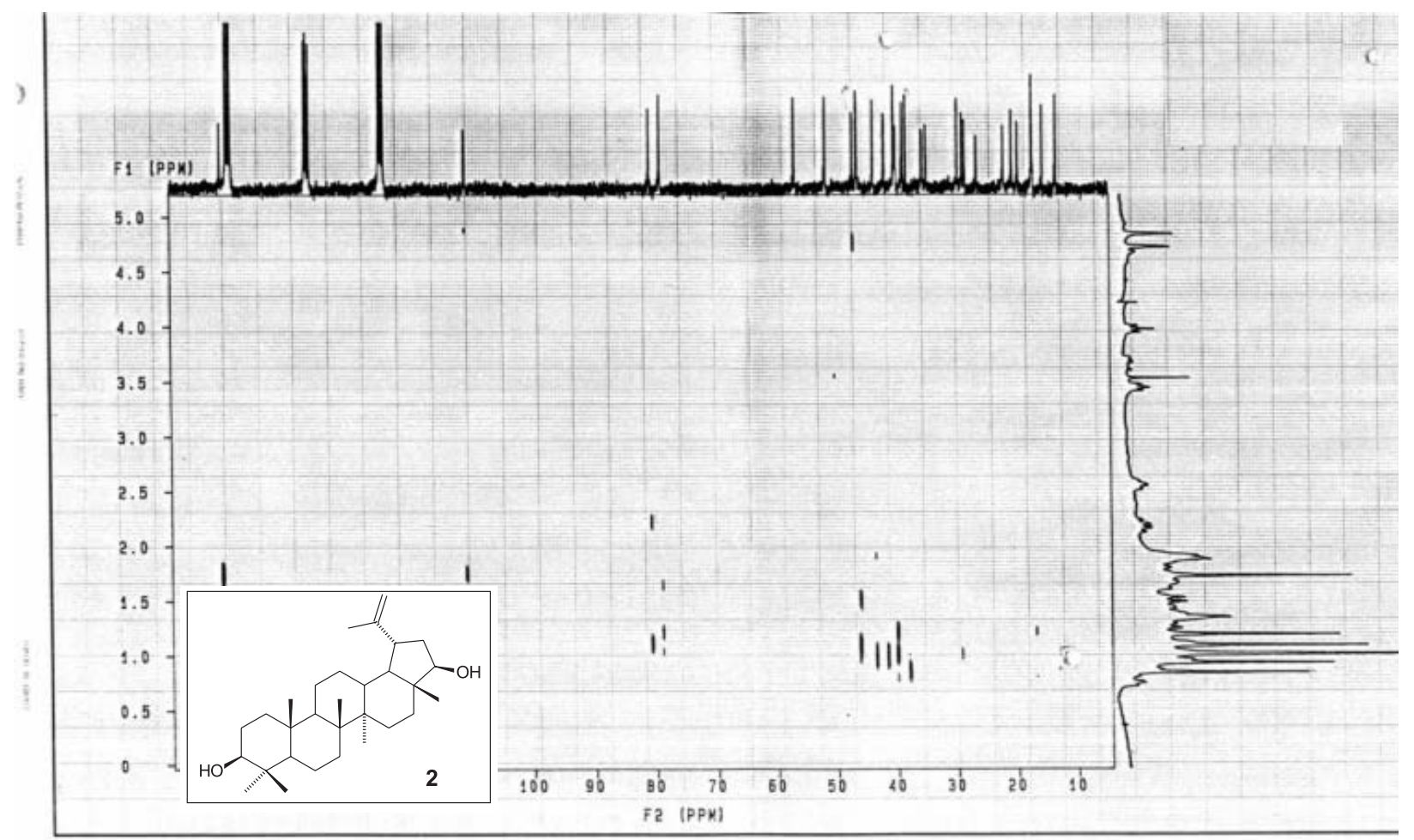

Figure S7. ${ }^{13} \mathrm{C} \mathrm{x}{ }^{1} \mathrm{H} \operatorname{COSY}(J 140 \mathrm{~Hz})$ of compound $2 \mathrm{CDCl}_{3}$.

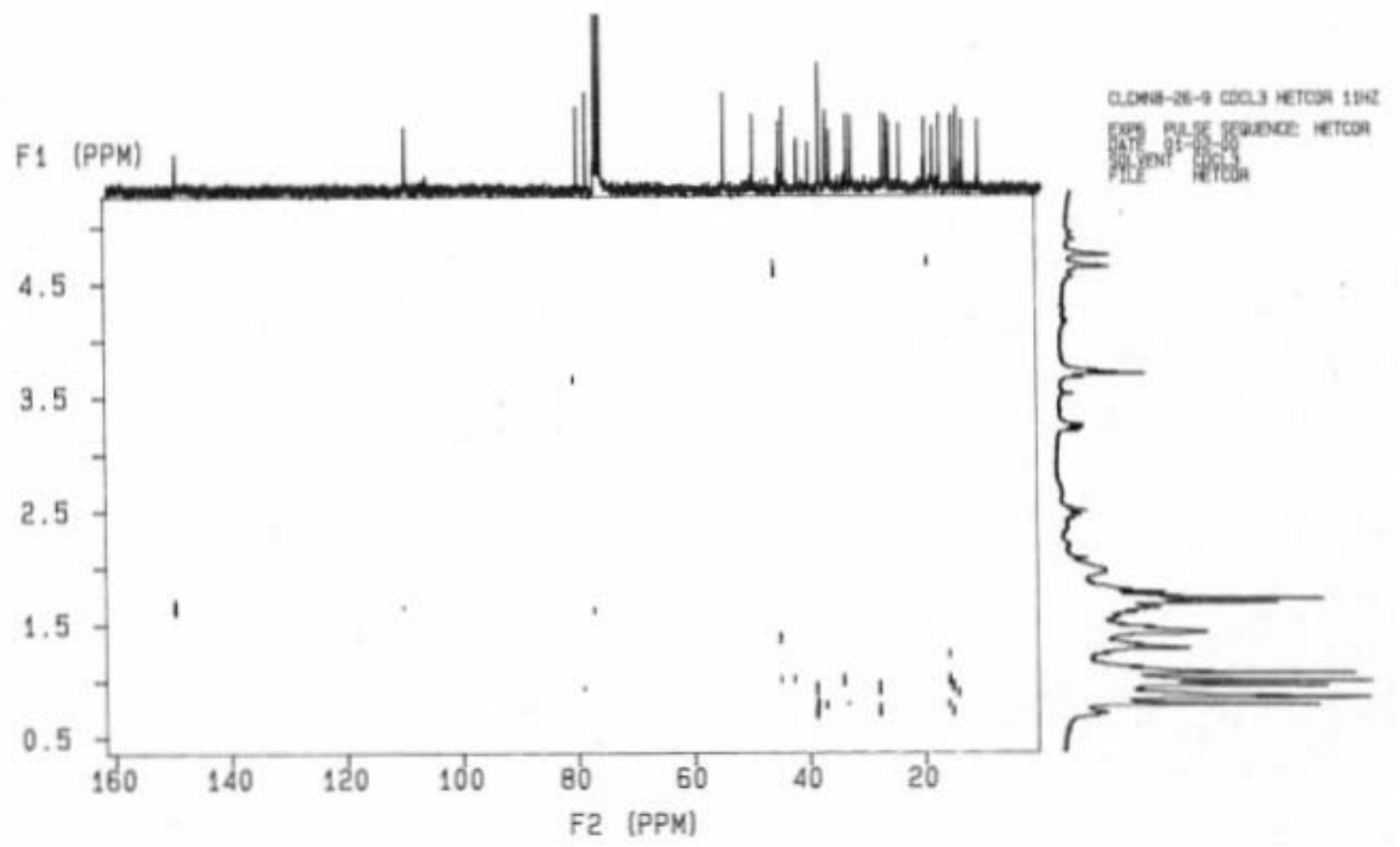

Figure S8. ${ }^{13} \mathrm{C} \mathrm{x}{ }^{1} \mathrm{H} \mathrm{COSY}(J 11 \mathrm{~Hz})$ of compound $2 \mathrm{CDCl}_{3}$. 


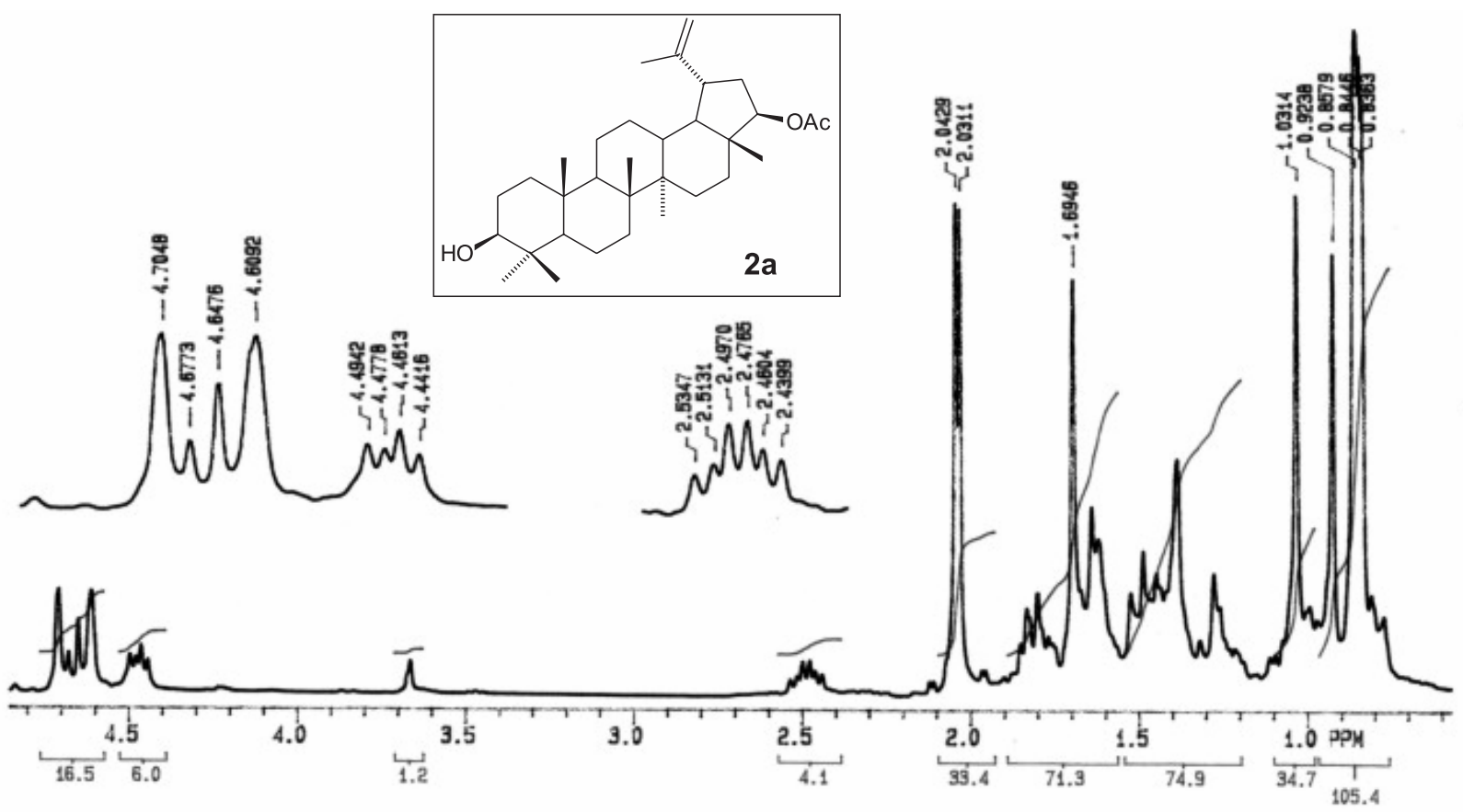

Figure S9. ${ }^{1} \mathrm{H}$ NMR of compound 2a $\left[300 \mathrm{MHz}, \mathrm{CDCl}_{3}, \delta\right.$ (ppm)].
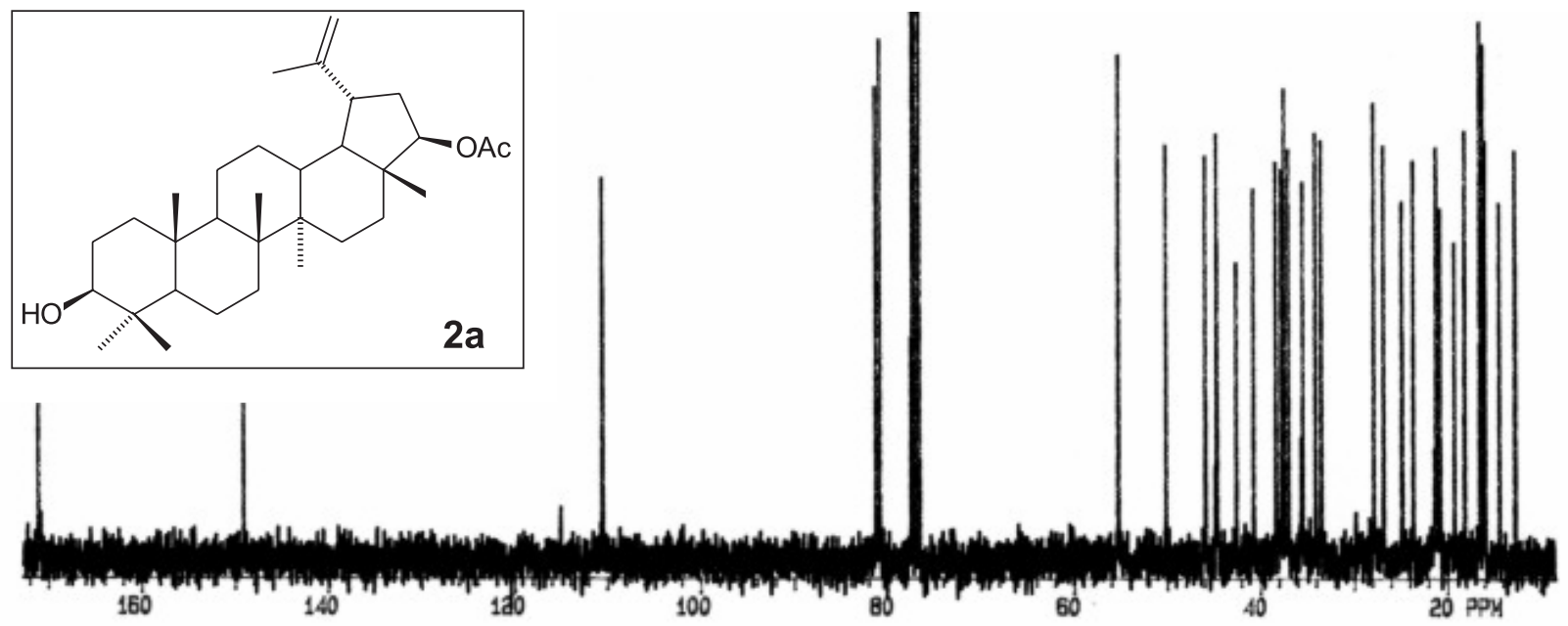

Figure S10. ${ }^{13} \mathrm{C}$ NMR of compound 2a $\left[75 \mathrm{MHz}, \mathrm{CDCl}_{3}, \delta(\mathrm{ppm})\right]$. 


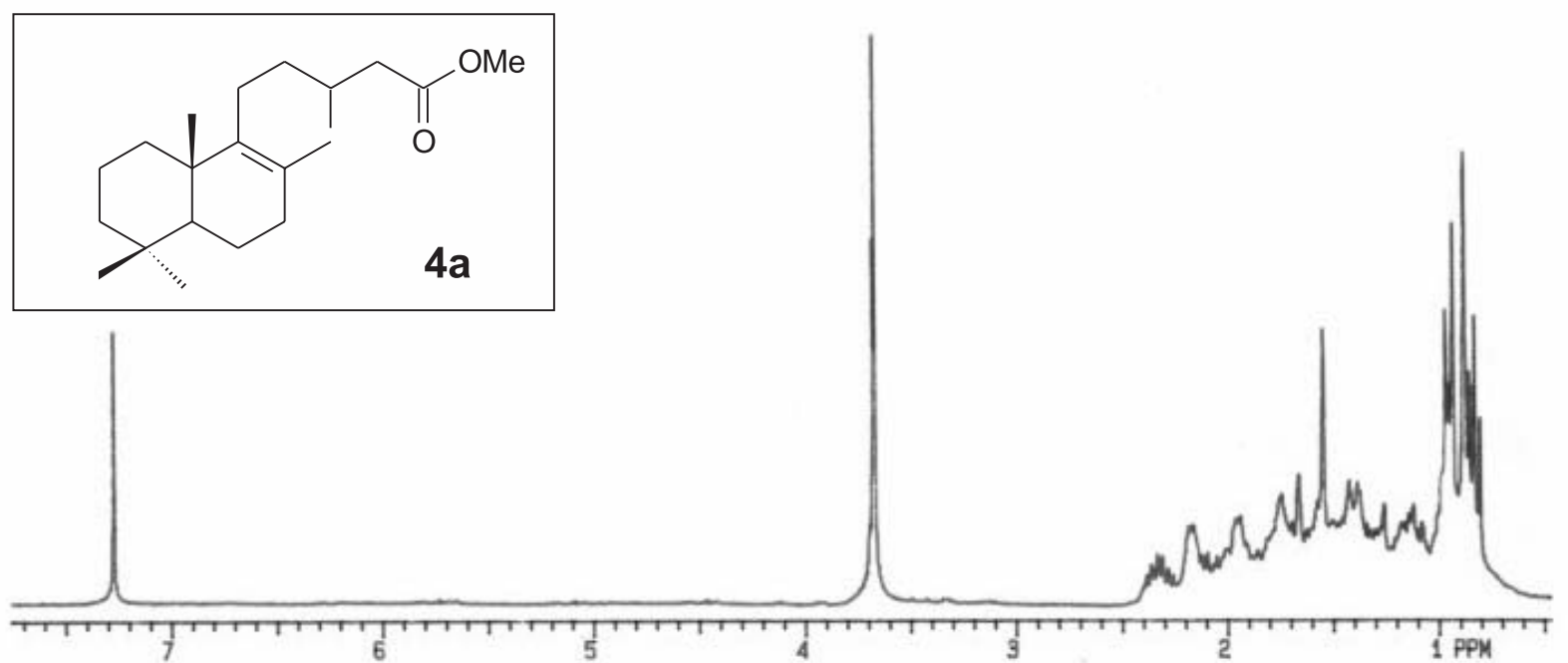

Figure S11. ${ }^{1} \mathrm{H} \mathrm{NMR}$ of compound $4 \mathbf{a}\left[300 \mathrm{MHz}, \mathrm{CDCl}_{3}, \delta(\mathrm{ppm})\right]$.

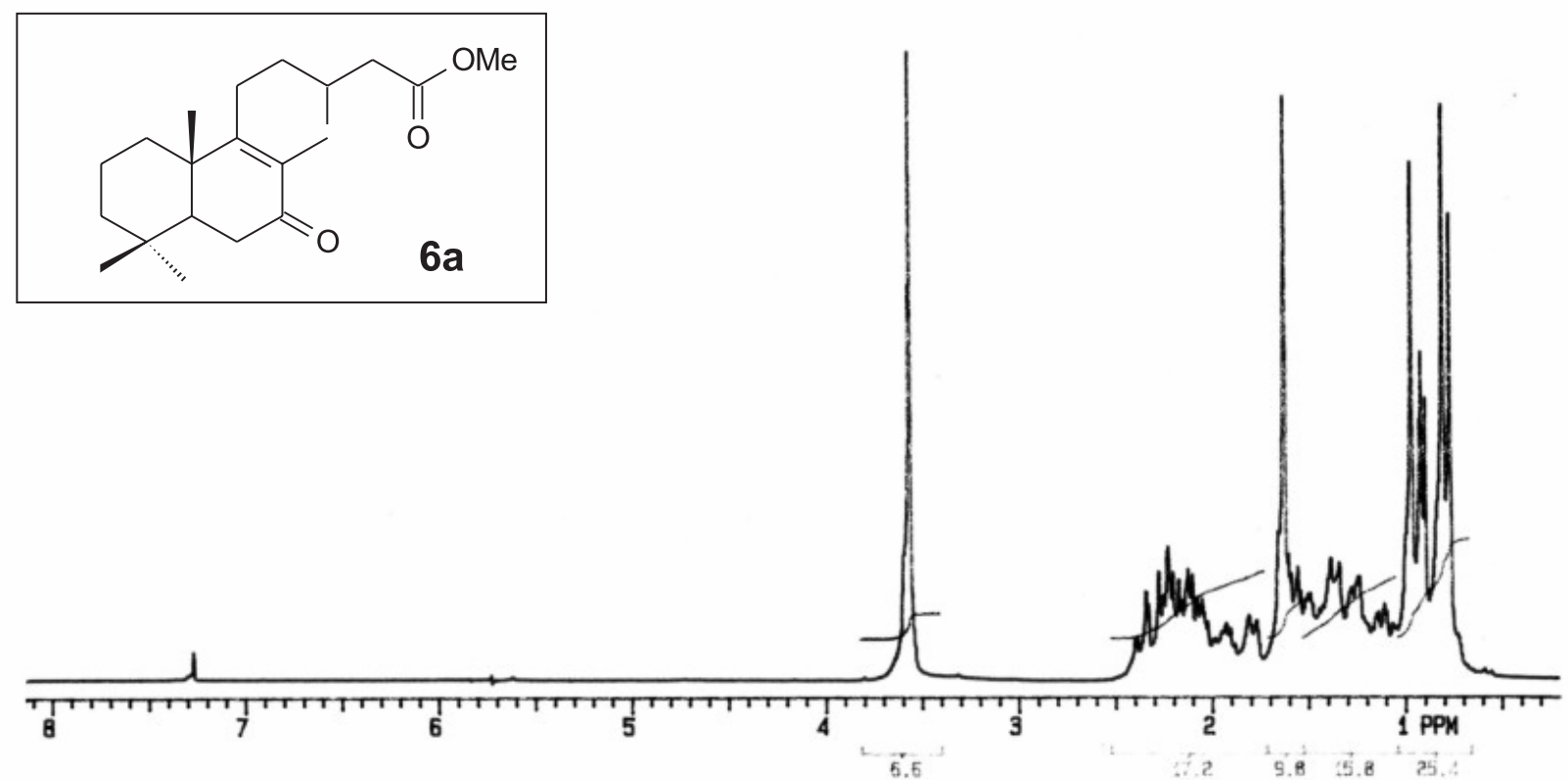

Figure S12. ${ }^{1} \mathrm{H} \mathrm{NMR}$ of compound 6a $\left[300 \mathrm{MHz}, \mathrm{CDCl}_{3}, \delta(\mathrm{ppm})\right]$. 

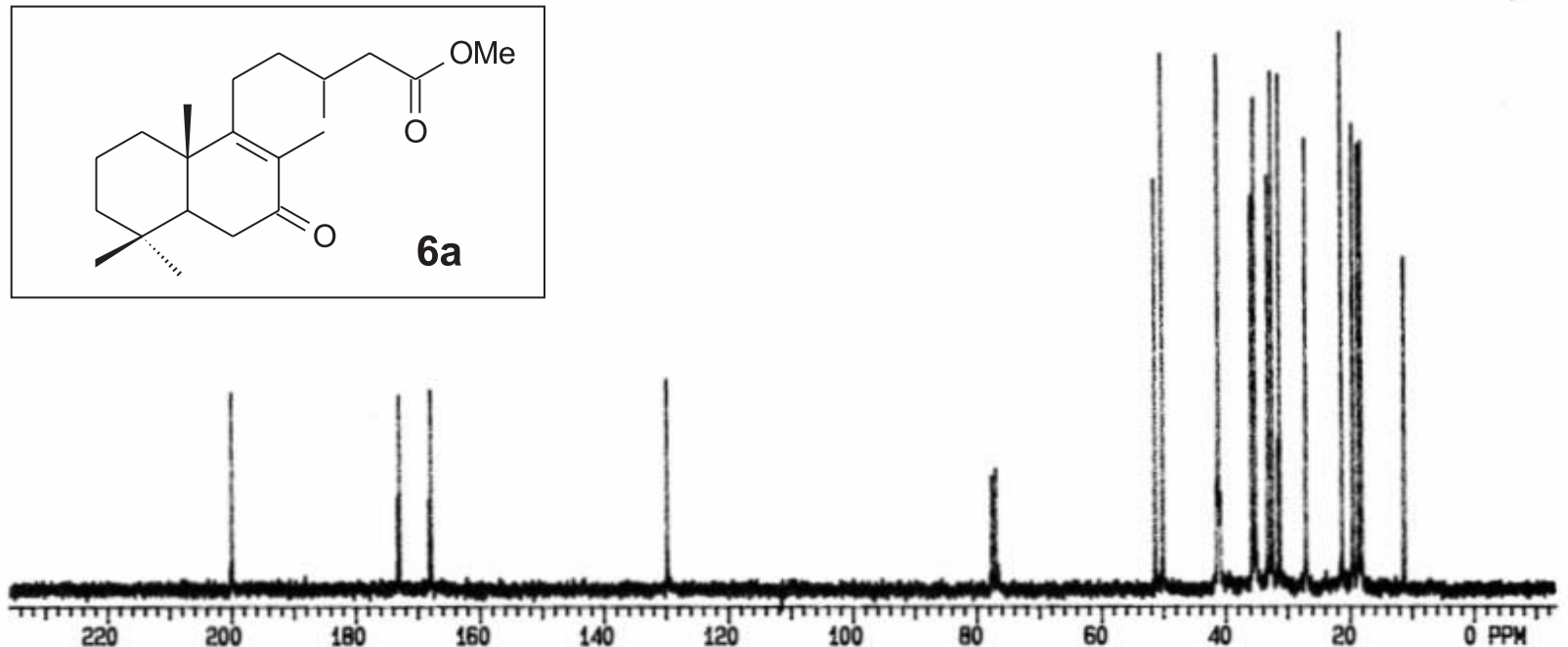

Figure S13. ${ }^{13} \mathrm{C}$ NMR of compound 6a $\left[75 \mathrm{MHz}, \mathrm{CDCl}_{3}, \delta(\mathrm{ppm})\right]$. 